\title{
INCONGRUENCIAS EN LOS USOS DE LOS IDEARIOS DE LIBERTAD E IGUALDAD*
}

\author{
Carlos Ruiz Encina \\ Universidad de Chile
}

\begin{abstract}
Resumen: Para el autor de esta conferencia, en el Chile de la transición, ni el desarrollo del mercado ha significado más libertad, ni el desarrollo del Estado ha significado mayores posibilidades de igualdad para la población. Esto, porque, más allá de adoptar los grandes discursos de legitimación del último siglo — liberalismo económico y socialdemocracia-, los resultados concretos de la sociedad construida en más de 25 años de régimen democrático reflejarían un divorcio entre política y sociedad. El autor propone, entonces, el estatuto de la política en la construcción de la sociedad como paradigma de libertad y democracia.

Palabras Clave: política, liberalismo económico, socialdemocracia, transición chilena, desigualdad.
\end{abstract}

\section{INCONSISTENCIES IN THE USE OF THE IDEAS OF FREEDOM AND EQUALITY}

Aвstract: The development of the market in post-dictatorship Chile has not brought greater freedom, in the view of the author of this lecture, and nor has the development of the State given the population greater opportunities for equality. This is because politics has be-

Carlos Ruiz Encina. Sociólogo y doctor en estudios latinoamericanos por la Universidad de Chile. Profesor del Departamento de Sociología de la Universidad de Chile. Email: cruizencina@uchile.cl.

* Versión revisada de la conferencia realizada en el simposio “¿Es la desigualdad un problema político?", llevado a cabo el martes 6 de septiembre de 2016 en el CEP. 
come increasingly divorced from that society even as it has adopted the last century's great legitimation discourses, economic liberalism and social democracy. The discussion proposed by the author concerns the status of politics in the construction of society as a paradigm of freedom and democracy.

KeYwords: politics, economic liberalism, social democracy, Chilean transition to democracy, inequality.

\section{EL PAPEL Y LOS ALCANCES DE LA POLÍTICA EN LA CONSTRUCCIÓN DE LA SOCIEDAD. LOS MODOS DE LA DISCUSIÓN}

partir de los ideologismos que inundan la cuestión de la desigual-
dad, los discursos de legitimación en boga y las naturalizaciones más extendidas, una discusión acerca del carácter político de la desigualdad tiene que comenzar señalando las relaciones no siempre directas entre éstos, con la finalidad de situar el problema en discusión.

La pregunta por la pertinencia de atribuir una naturaleza política a la desigualdad social contiene el dilema implícito acerca de si esta última no es más bien un asunto del mercado, asunto en el cual la primera no debiera intervenir. Si no, entonces, ¿por qué hacerse tal pregunta? Esto, a su vez, contiene otro implícito, sostenido por las ideologías vigentes: dado que la desigualdad social es un asunto del reino de la libertad y del universo del individuo, entonces, sobre él no debe actuar regulación, intervención ni planificación alguna, acciones estas últimas usualmente atribuidas al ámbito estatal e, incluso, a la política en general. De modo que, frente a las ideologías más proclives al mercado, la pregunta acerca de si es la desigualdad un problema político, remite a abrir los supuestos de dichos ideologismos e inquirir acerca de los alcances y el papel de la política en la sociedad.

La cuestión estriba — de forma más general — en el estatuto de la política en la sociedad y su rol en la construcción de la sociedad. En específico, se trata del papel de la política en la producción de la diferenciación social, de la desigualdad. Como contraparte, ello nos lleva a la cuestión de la autonomía de la economía (entendida como mercado, a la usanza) respecto de la política. En definitiva, se trata también, en forma concomitante, del estatuto del mercado en la sociedad. 
Con la modernidad, en una sociedad secularizada y presidida por la razón, ¿la construcción de la sociedad debe ser pensada? ¿Es un asunto racional? ¿Debiese, en este sentido, ser la política el espacio de deliberación racional, democrático y justo para ello?

De gran relevancia, esta discusión se ancla en la base de la construcción de alternativas políticas y, con ello, en la de los procesos de construcción de la cultura política. En la actual situación deficitaria de extendida desidentificación con la política por parte de la sociedad, se trata de una cuestión que actúa sobre los vacíos de la cultura política vigente $\mathrm{y}$, con eso, en los déficits de sentido de la propia política y su crisis de legitimidad. Como una preocupación responsable ante esta situación, cabe consignar un renacimiento de lo político en el debate de ciertos sectores más lúcidos de la derecha chilena, que es lo que anima esta discusión.

\section{DIFERENCIACIÓN SOCIAL Y ORDEN. LA DESIGUALDAD Y SU LEGITIMACIÓN}

El problema de la desigualdad, para los sociólogos, forma parte de uno más general, a saber, aquél de los modos de diferenciación social que tienen lugar en la producción de una sociedad concreta. De ahí, el desarrollo de un cúmulo de teorías de la diferenciación social, que aquí no viene al caso repasar.

El interés por estas cuestiones es de naturaleza política; una naturaleza que a menudo ocultan los enfoques técnicos, asépticos políticamente hablando, usualmente expresados en catálogos generales de divisiones sociales existentes, escasa o nulamente jerarquizadas, que no apuntan a las relaciones e interdependencias que existen entre ellas. Se suele restringir el retrato a simples descripciones, que ignoran las formas de producción de dichas diferenciaciones sociales, y se abstraen así de esfuerzos comprensivos e interpretativos que aborden la sociogénesis de estos procesos. El problema está en las relaciones de poder que subyacen en la producción del conjunto de jerárquicas diferenciaciones sociales que hacen a la sociedad en cada momento dado. El hecho de que los factores y los modos que intervienen en ello no sean siempre los mismos tiene que ver con esas relaciones de poder históricamente 
cambiantes: con las transformaciones históricas en las fuentes de poder y su incidencia en los modos de producción de la diferenciación social $\mathrm{y}$, en particular, de las modalidades de desigualdad vigentes en cada momento.

De ahí que las distintas teorías de la diferenciación social desarrollan, en cada etapa, una estrecha relación con la producción y legitimación del orden social. Como se sabe, todas las sociedades relativamente complejas se caracterizan por la desigualdad en la distribución de la riqueza material y social, aun cuando ello ocurra en distintos grados y formas. Y esas distintas estructuras de desigualdad económica y social se han acompañado, de modo sistemático, de algún tipo de formulación ideológica - y teórica en tiempos contemporáneos- que pretende explicar y justificar la desigual distribución de los recursos existentes en la sociedad. De ahí que existe una vinculación entre los modos de comprensión de las diferencias sociales y las pretensiones de construcción del orden social.

La idea del origen natural de las desigualdades sociales que impera en la sociedad tradicional infundía a las relaciones sociales un carácter preconcebido e inmutable, que excluía cualquier deliberación al respecto por parte del pensamiento social. Es decir, se trataba de una apreciación de las desigualdades sociales acompañada de expandidas y arraigadas justificaciones morales y religiosas. Pero aquellas sociedades y la rigidez social de sus sistemas de diferenciación social sucumben bajo los dinámicos tiempos que, entre los siglos XVII y XIX, corren con el avance de un industrialismo capitalista que se asocia al advenimiento de la modernidad. Con esos cambios llega la crítica de los sistemas tradicionales de creencias, que por casi dos milenios explicaron y legitimaron las desigualdades sociales. Llega el supuesto de que los seres humanos nacen iguales, y con él las explicaciones del pensamiento social sobre la desigualdad. Descartado el origen de la desigualdad derivado de una condición "natural" de los individuos, hay que buscar en otra parte la explicación de las desigualdades. Si ésta no tiene un origen "natural", ¿qué hace desiguales socialmente a los individuos?, ¿por qué unos dominan a otros? Desde entonces, tales preguntas pasan a constituirse en la base de los problemas centrales de la teoría social y política.

En el pensamiento político, los contractualistas formulan las primeras respuestas. Hobbes apunta a que la vida en el estado de natura- 
leza constituye un peligro, que resulta marcada por la guerra entre los hombres. En tal perspectiva, la solución a este "problema del orden" es la sumisión al Estado, sin la cual no habría más que caos. A la idea del Estado hobbesiano, Locke, en una línea que se juzga liberal, agrega que la autoridad del Estado es la que mejor puede garantizar los "derechos naturales" a la vida, la libertad y la propiedad. Más tarde, Rousseau precisa que, sin que se pueda alcanzar la libertad absoluta, la democracia directa, expresada por medio de la "voluntad general", es un sistema político capaz de proporcionar la mayor protección al individuo. Se forjan así los fundamentos de la idea de que todos los "ciudadanos" tienen derechos políticos, tal y como se expresa en el sufragio universal y las instituciones democráticas. Un contractualismo en cuya base está el principio de una relación de protección y obediencia entre el Estado y la ciudadanía.

Con el ocaso de la sociedad tradicional y el avance del industrialismo crece el énfasis en la racionalidad del orden social moderno. Al mismo tiempo, se corroe el viejo reconocimiento social de las normas de la costumbre, y se expande el cálculo racional como fundamento de la nueva conducta económica en las sociedades capitalistas. La expansión de los mercados y los cambios en los procesos de producción avanza junto con la erosión de los derechos consuetudinarios en el dominio del comercio y la manufactura. A un tiempo, los cambios políticos que crean el individuo formalmente libre también producen al trabajador sin tierra, con el derecho a vender lo único que posee: su capacidad de trabajar. El trabajo se convierte en mercancía. Unas "libertades burguesas" que Marx critica en el siglo XIX, apuntando a los modos de legitimación del orden social en ascenso: el poder del Estado resulta inseparable del poder económico, y el "individuo soberano" de esta era deviene condición necesaria para la moderna explotación capitalista. Tal igualdad política resulta imprescindible para coexistir con las desigualdades materiales, puesto que, al definir las desigualdades vinculadas al sistema moderno de producción, distribución e intercambio como "no políticas", la ideología burguesa las legitima (Marx 1967).

La idea de modernidad asociada al desarrollo del industrialismo capitalista incluye también los modos de control y regulación de las formas de sociedad que se le vinculan, con lo cual el Estado nacional se erige como uno de los más característicos, marcado por el desarrollo 
de organizaciones y sistemas reflexivamente controlados con capacidad de actuar sobre el mundo social, los que intervienen de modo decisivo en la constitución de las diferencias sociales. Las desigualdades relacionadas con las estructuras de producción, distribución e intercambio se tornan centrales en este panorama, aunque las formas anteriores de diferenciación social no desaparecen de inmediato. Al contrario, su persistencia le imprime mayor complejidad al problema al hacer inteligible la construcción de la sociedad, dada tal prolongación de instituciones precapitalistas que resulta, por lo demás, especialmente relevante en sociedades como las latinoamericanas. Las desigualdades consuetudinarias, en particular las que se relacionan con los estatus adscritos al origen familiar, el género, el fenotipo o la edad, persisten como una suerte de "legado moral" de las instituciones precapitalistas. Los grados que alcanza esta determinación política en el acceso a la riqueza, y con ello en la diferenciación social, relativizan el peso de mecanismos propios de situaciones de mercado en este sentido. ${ }^{1}$

En la actualidad, también se produce esta relación entre las pretensiones de construcción del orden social y las formulaciones teóricas e ideológicas en torno a la diferenciación social. Economistas como Hayek señalan que la persecución del interés propio en la sociedad propicia la innovación y el avance tecnológico, echando las bases de las doctrinas neoliberales. En esta línea, el capitalismo resulta dinámico porque es desigual y los intentos dirigidos a anular dicha desigualdad - o sea, a propiciar la igualdad - significan una limitación a la iniciativa individual que, en tal perspectiva, constituye el motor económico principal de la abundancia y el desarrollo material de la sociedad. Dichos argumentos tienen su paralelo en la teoría funcionalista de la estratificación, de raíces en el funcionalismo estructural parsoniano, para la cual, en las sociedades industriales avanzadas, los individuos deben ser inducidos a prepararse para ocupar posiciones que exigen mayores niveles de cualificación, y a cambio deben recibir una compensación proporcional a ello. ${ }^{2}$

Se postula que en las sociedades industriales, propias de una compleja división del trabajo, se produce un nuevo consenso sobre la igualdad, que sustituye al tradicional, anclado en la costumbre y las per-

\footnotetext{
${ }^{1}$ Ver las referencias clásicas en Weber (1964).

${ }^{2}$ Una formulación clásica en Davis y Moore (1972).
} 
cepciones religiosas, no racionales, de la riqueza; que es expresivo de la racionalidad de la sociedad moderna. Los diferentes grupos no aparecen como antagónicos: son "estratos" socioeconómicos más que "clases". Así, la desigualdad en las sociedades modernas se legitimaría en virtud de un consenso de valores sobre la importancia societal de determinadas funciones consideradas fundamentales para el progreso económico y social. En tanto discurso de legitimación o justificación moral de la desigualdad económica, esta formulación se afirma en un presupuesto fundamental: la existencia de una situación de igualdad de oportunidades; un axioma central del pensamiento liberal, con el que empalma la elaboración de Rawls $(1979 ; 1993)$ y una filosofía moral que busca hacerlo compatible con las desigualdades reales. De ahí la centralidad de las condiciones y la posibilidad de la igualdad de oportunidades en la construcción del orden social actual y su legitimación, en tanto poderosa justificación de la desigualdad. Si todos tienen las mismas oportunidades de ser desiguales, el resultado desigual parece justo y justificado como reflejo de las desigualdades entre los talentos personales y no de procesos sociales prefigurados. Se trata de la explicación y justificación de las desigualdades materiales en una sociedad que reconoce política y jurídicamente la igualdad.

Si para Marx la desigualdad de clase se funda en el acceso diferente a la propiedad y al control de los recursos productivos, y es la base de una situación que no es consensual sino eminentemente conflictiva, también los "teóricos del conflicto" — como el propio Weber o Dahrendorf (1962) - relevan la importancia del poder y la coerción en la explicación de la desigualdad, e identifican las clases sociales como los "actores" principales de las sociedades industriales, aunque no pronostican la ruptura del orden social.

\section{ANTECEDENTES Y CONTEXTOS DE LA DISCUSIÓN SOBRE LOS ALCANCES DE LA POLÍTICA}

En la sociedad moderna, la cuestión de la diferenciación social - las desigualdades - y el orden social remite al problema del estatuto del mercado en la sociedad. ¿Debe éste tener una supremacía sin restricciones o debe, en cambio, tener una posición subordinada en la sociedad? Es un debate de largas raíces, especialmente agitado en el 
período entreguerras, y se relaciona con las preguntas que hoy se reiteran a partir de las experiencias del llamado neoliberalismo. ¿Es posible amansar la furia del mercado - y las disparidades sociales que produce - en una sociedad situada bajo una dinámica económica cada vez más global? Para quienes el aumento de la riqueza y del progreso social sólo es posible en una sociedad en que domine el mercado, tal dilema ni siquiera existe. Pero es un largo debate, que agrega progresivamente nuevas complejidades, evitando una clausura simple de esta cuestión.

La pregunta se reformula: ¿cómo compatibilizar el desarrollo del mercado con el interés general? Sus raíces pueden rastrearse, al menos, a fines del siglo XVIII, a la revolución industrial inglesa y la revolución política francesa, fundantes de los paradigmas económicos y políticos de la modernidad. Entre tales elaboraciones, aparece en Alemania, después de la Comuna de París, un modelo en que el Estado interviene en diversos asuntos de interés común, coexistiendo con la propiedad privada, manteniendo bienes de propiedad social. Un tipo de propiedad que no sólo es la única propiedad de quienes carecen de propiedades, es decir, los más pobres, sino que además tiene pretensiones de erigirse en instrumento y espacio de cohesión institucional (Álvarez-Uría 2005).

Esta discusión es el antecedente de los debates actuales, y adquiere especial intensidad en la crisis de la sociedad europea de entreguerras, cuando la crisis económica, la revuelta obrera y el desplome de la clase media someten a una enorme presión al orden vigente. De esa crisis centroeuropea, la discusión se traslada a Inglaterra y luego se arraiga, como pensamiento del siglo XX, en los Estados Unidos. Si ya en Weber hay una preocupación temprana por la planificación a través de políticas sociales — que apunta a los problemas de la integración social y a la desigualdad como una amenaza a la primera, al mismo tiempo que advierte sobre los excesos del poder burocrático que aprecia en credos autoritarios de un extremo y otro- , llega con Polanyi, en realidad, la discusión abierta y el cuestionamiento del estatuto del mercado en la sociedad. Un debate que transcurrirá bajo el contexto de la solución keynesiana a la cuestión del desempleo.

El ideal de una sociedad de mercado alcanza una primera formulación bajo el liberalismo manchesteriano. Como utopía económica se abre paso ya a finales del siglo XVIII con los representantes de la economía política escocesa, extendiéndose sobre los países occidenta- 
les en el siglo XIX, buscando una primacía autonomizada del mercado en la sociedad, para que domine toda la vida social. Para Polanyi, tal utopía desarticuló las viejas instituciones sociales heredadas y posibilitó, en la primera mitad del siglo XX, los Estados totalitarios bajo el fascismo. De tal modo, para entender el nacionalsocialismo alemán, hay que remontarse a la Inglaterra de Ricardo. En La gran transformación, Polanyi (1992) examina las condiciones sociohistóricas que favorecen el ascenso del mercado a un sitial hegemónico en las sociedades capitalistas; un marco social e intelectual que es preciso recuperar para situar las preocupaciones del presente.

En aquellas condiciones, grandes sucesos se mezclan en la agitada primera mitad del siglo XX, como el debate sobre la Revolución Rusa y las posibilidades de desarrollo de una economía sin mercado; la gran crisis del 29, el New Deal norteamericano y las propuestas de Keynes; la oposición antikeynesiana de la escuela austríaca de economía y las bases del ideario neoliberal; y el propio avance de los totalitarismos, la Segunda Guerra Mundial, la gran crisis y reconstrucción de la civilización occidental. Polanyi y otros intelectuales como Norbert Elias y Karl Mannheim, que asistían al horror de la Primera Guerra Mundial, al derrumbe del viejo Imperio Austrohúngaro, al ocaso del precario parlamentarismo de la Alemania posterior a Versalles y al inicio de los movimientos revolucionarios y los totalitarismos, abordan estas cuestiones en tiempos de gran incertidumbre.

La Revolución Rusa instalaba no sólo el problema del cambio anticapitalista, sino también, relativo a nuestra discusión, la cuestión del cálculo económico. Sobre el futuro del socialismo ruso, Weber advertía tempranamente las dificultades que traería el peso de la larga tradición autocrática zarista, por lo que esta aventura retrasaría - en lugar de adelantar - la llegada del socialismo. La advertencia weberiana estaba en línea con su idea de la necesidad del dinero para una planificación económica racionalizada; argumento que los economistas austríacos avanzan más allá de la preocupación de Weber, para afirmar la imposibilidad del socialismo en cualquier sociedad. Ya antes de que estalle el curso revolucionario ruso, Ludwig von Mises publica la Teoría del dinero y del crédito, en 1912, y, luego, un artículo en el Archive für Sozialwissenschaft und Socialpolitik, la clásica revista fundada por Weber, en 1920, planteando la imposibilidad de una economía socialista en una 
forma trascendente y vinculada a la discusión que hoy nos ocupa. El Estado, al fijar arbitrariamente los precios torna inviable - sosteníael cálculo económico, porque las necesidades de la población se expresan a través de la demanda efectiva, pero el único medio de acceder a tal demanda es el mercado. Sin el mercado, ni libertad de compraventa, ni competencia libre, no hay precios, y sin precios que reflejen las prioridades e intereses de los consumidores no es posible el desarrollo de una racionalidad económica que responda al interés general. Mises impugnaba el socialismo en nombre de la revolución marginalista, desde una nueva teoría económica que ubica al empresario en un sitial central y en la que la libre elección del consumidor eclipsa al trabajo como fuente de la riqueza.

Polanyi (2008) critica esta formulación por tautológica y reclama una vía entre el liberalismo de los austríacos y el colectivismo soviético. El problema estriba — apunta - en situar de modo reflexivo la cuestión del lugar de la economía en la sociedad, algo que tanto el economicismo liberal como el estalinismo impiden abordar. Tras la Gran Depresión de 1929, el debate entre Polanyi y Mises cobra nueva importancia. Las opciones políticas se cerraban en torno al socialismo soviético, el fascismo, el reformismo socialdemócrata y el liberalismo. Si la opción socialdemócrata se asocia en un inicio a Roosevelt y su New Deal, abocado a compatibilizar planificación y libertad, Keynes formula la necesidad de una institución capaz de un "control deliberado de la moneda y del crédito", en la idea de que, ya antes de la crisis, las sociedades industriales transitaban de un capitalismo de pequeñas empresas familiares a un capitalismo socializado, marcado por la emergencia de grandes corporaciones privadas. El reformismo de Polanyi, como el de Mannheim, apuntaba a una economía alternativa tanto al liberalismo económico, como al fascismo y al sistema soviético.

¿Cómo articular la planificación con libertad, la lucha en favor de la igualdad con las libertades de los individuos? Éste era el dilema que animó una elaboración que buscaba superar el individualismo liberal, defendido por Mises y Hayek, que asociaba a la civilización occidental con la sociedad de mercado, que veía en la planificación un control central que no sólo excluía la libertad de los individuos, sino que además llevaría inevitablemente a la agonía de una técnica que se desarrolla — según tal visión — en la medida en que exista libre competencia. Pero 
la revolución keynesiana se impone en esa oportunidad sobre los economistas liberales seguidores de la escuela austríaca de economía. Si Hayek alega la necesidad de garantizar las condiciones para un equilibrio entre la producción de bienes y consumo - en la idea de que en los precios anida la posibilidad de un conocimiento racional del mercado por los individuos, invocando "la mano invisible" de Smith como fuente de un orden estable-, Keynes, en lugar de partir de tal estabilidad - regida por la libre concurrencia y la confianza en el curso espontáneo del mercado-, formula una economía de la crisis. Invierte los términos de los austríacos, alega que el mercado es incapaz de resolver por sí solo los desajustes que genera, lo que plantea la necesidad de una instancia externa que introduzca desde fuera del mercado la regulación económica. Critica, entonces, a Mises por una aversión a la política y al Estado; es decir, al intervencionismo.

Los embates del liberalismo, en un inicio dirigidos hacia el marxismo ortodoxo, giran hacia esta formulación keynesiana orientada a legitimar, en nombre del interés general y a partir de las categorías económicas, el recurso al intervencionismo. En 1938, en un encuentro en París realizado a propósito de las inquietudes del periodista y ensayista norteamericano Walter Lippmann, encuentro que luego se conocerá como el Coloquio Lippmann, se coincidía en la necesidad de articular un nuevo liberalismo. De ahí que, en esa oportunidad, se acuñe el célebre término "neoliberalismo". Hayek y Robbins trazan los ejes trascendentes: sólo el mecanismo de los precios, operando en mercados libres, permite una utilización óptima de los recursos productivos orientada a la satisfacción máxima de los deseos humanos; la responsabilidad del Estado estriba en establecer el marco jurídico para tal libre desarrollo económico; otros fines sociales pueden ser atendidos con cargo a la renta nacional que, con esa finalidad, puede ser sustraída al consumo, siempre que tal transferencia cuente con un consentimiento transparente. ${ }^{3}$ De este modo, ante la amenaza del comunismo y el totalitarismo, la clave técnica invocada es el mecanismo de los precios. La apelación es a la necesidad de recurrir a la "iniciativa individual para buscar la ganancia, asumiendo con ello las responsabilidades y riesgos" (Wapshott 2013). El debate sobre la imposibilidad del cálculo económico en el so-

\footnotetext{
${ }^{3}$ Según la síntesis de Baudin (1952), citada por Álvarez-Uría (2005).
} 
cialismo y en las economías planificadas se plantea ahora en torno a "el mecanismo de los precios".

A pesar del avance de la solución keynesiana, la trascendencia del Coloquio Lippmann radica en que cohesiona la determinación de un grupo de intelectuales en la defensa de la primacía del mercado en la sociedad que, más que centrarse en el viejo liberalismo, se plantea la elaboración de un liberalismo de nuevo cuño. Al año siguiente se creaba, en el mismo París, el Centre International d'études pour la Renovation du Liberalisme, una organización que resulta el precedente directo de la más conocida Sociedad Mont-Pelerin, que surge en torno a Hayek en 1947.

En este nuevo liberalismo hay una concepción del hombre como tal. Polemizando con Mises, Polanyi contrasta la asociación del individuo con el homo oeconomicus de origen en la tradición de la economía política escocesa, y con el yo psicológico de la tradición psicoanalítica. Tal como Keynes, Mannheim o Norbert Elias, insiste en un yo conformado por las interacciones y las instituciones sociales. Mannheim recupera la concepción de la subjetividad de Malinowski en su célebre Los argonautas del Pacífico occidental, en el que discute con el psicoanálisis sobre el complejo de Edipo y releva la primacía de los factores culturales en el moldeamiento de los individuos sobre aquellos económicos y estrictamente psicológicos. En igual línea situaba Elias las diferencias conceptuales entre civilización y cultura en El proceso de civilización. Investigaciones sociogenéticas y psicogenéticas, de 1939 (Elias 1987). El mercado no quedaba por encima de la sociedad. Pero, apelando a la tradición de la centralidad del "hombre económico", este nuevo liberalismo hace de la elección del consumidor un factor psicológico inherente a la condición humana, que está en la base de la economía, y en especial del sistema de precios, trazando una naturalización de las relaciones de mercado que tendrá una enorme expansión posterior.

Mannheim aprecia en aquellos años treinta un curso de cambio social acelerado desde la vieja sociedad liberal, amparada en la democracia de minorías, a una sociedad de masas. La política de gobernantes aristócratas y electorados restringidos, presupuestos modestos y divisas estables se desplomaba tras el desastre de la Primera Guerra Mundial y el ascenso bolchevique en Rusia. Nuevas expectativas sobre una democracia capaz de procurar mayor seguridad e igualdad, y capaz de acabar 
con las barreras tradicionales entre el sistema político y la iniciativa empresarial, chocaban en Europa con los vestigios semioligárquicos en el Estado y las jerarquías sociales. En la sociología, crecía la atención sobre los rasgos y dilemas de la nueva "sociedad de masas". El avance industrial y el desarrollo tecnológico se acompañaban de una crisis de la cultura, cifrada en la ausencia de "capas sociales sublimadoras" a cargo de "conformar de modo primario las fuerzas espirituales y anímicas" (Remmling 1982). Opuesto a los pensadores proclives al elitismo tradicional, Mannheim aprecia como indetenible el proceso de democratización de masas, y advierte las complejas necesidades de orientación. Declaraba así cerrado el ciclo del liberalismo clásico, y abría el dilema de la democracia en tiempos de la sociedad de masas, cuyo nacimiento implicaba cambios sociales incompatibles con la tradición liberal. El debate abarcaba la cuestión de los valores. El asunto era ir más allá de una sociedad de mercado sometida a los criterios de rentabilidad económica, cuyo afán de lucro desatado generaba pesadas fracturas sociales. En plena Segunda Guerra Mundial, las tareas que seguían a la devastación definían así el dilema de la "reconstrucción" de la democracia.

Las interpretaciones individualistas y economicistas de la vida social hallaban apoyo en las formulaciones de otro activo pensador en estos debates. A mediados de esos años treinta, entre Hayek y el joven filósofo austríaco Karl Popper surgía una alianza intelectual liberal, que proyectaría la obra de ambos al centro del ascenso del ideario neoliberal a fines de los años sesenta. Junto a la gravitación de Hayek en la crítica al "control central" de la economía y sus implicancias en términos de ineficiencia y autoritarismo, se introducía una dimensión relativa al "conocimiento científico", que aborda las tensiones entre planificación, ciencia y libertad. Las ideas de Hayek $(1937 ; 1941)$ al respecto reciben con Popper un impulso que alcanza la epistemología de las ciencias sociales.

En Camino de servidumbre, Hayek (2008) sintetiza sus críticas a la planificación, provenga de las experiencias socialistas o del occidente socialdemócrata, con una vehemencia que contrasta con el clima posbélico. Entonces, el mayor proyecto de planificación llegaba desde Estados Unidos. El "Plan de recuperación económica para Europa", conocido como Plan Marshall, se aprobó en el Congreso norteameri- 
cano forzado por el golpe de Estado comunista en Praga a inicios de 1948, con el fin de evitar la extensión de la influencia soviética. No sólo la lucha contra el hambre y la pobreza, sino que la reconstrucción de Europa contó con la ayuda norteamericana, aunque en un clima en que ya despunta la Guerra Fría. Desanimado por este ambiente, Hayek deja la discusión británica y desde el Chicago de los años cincuenta formula una teoría social y política más allá de su trabajo económico técnico, que deviene en la mayor síntesis de la derecha de posguerra (Anderson 2008). En Los fundamentos de la libertad (1960), luego en Derecho, legislación y libertad (1973-1979), proyecta una idea de libertad que opone la tradición empirista británica — que asume la evolución política como un curso espontáneo de gradual progreso institucional, asociable al de la economía de mercado o del derecho consuetudinario- al racionalismo francés, donde las instituciones sociales son susceptibles de construcción premeditada. Si la primera línea lleva a la libertad; la segunda la niega. Si Locke se erige en un eje para la auténtica libertad, Hobbes, visto como racionalista político, en el otro extremo estimula las ensoñaciones posteriores del positivismo jurídico; un constructivismo social que, como amenaza para este liberalismo, se imbrica con los riesgos de la democracia moderna. Hayek advierte que la igualdad ante la ley es un principio muy distinto al de la igualdad en la elaboración de la ley, en cuya confusión el segundo aplasta al primero, pues la idea de soberanía popular cobija la posibilidad de que el derecho público de las mayorías legislativas anule saberes heredados del derecho consuetudinario privado, transgrediendo los límites en torno a la propiedad individual y la persona. De ahí que, para garantizar el gobierno basado en el rigor de la ley, no en la licencia del consentimiento, sea preciso limitar la capacidad de injerencia general de estas asambleas; si bien la democracia es el modo de cambio más pacífico y efectivo para educar a las masas, tales ventajas no la convierten en un fin en sí mismo, ya que, en caso extremo, un régimen autoritario que reprima el sufragio popular pero respete el imperio de la ley podría garantizar mejor la libertad que un régimen democrático susceptible a las tentaciones de la redistribución social.

Ante el triunfo keynesiano, se insistía en limitar la incidencia de la política en la sociedad, y este nuevo liberalismo sobrevive aquella adversidad. En los años sesenta, con Friedman y el enfoque monetarista, 
dicho liberalismo logra adquirir capacidad política y de determinación sobre los modelos de desarrollo, y bajo la crisis de los Estados de bienestar se proyecta como una salida. Su ímpetu apunta nuevamente a la fórmula keynesiana, cifrando como el efecto más peligroso de esta fórmula a la interferencia estatal en la inflación. Ataca una acción estatal destinada a controlar los precios para garantizar acceso social. Desde esos orígenes de monetaristas de Chicago, el ideal de "autorregulación del mercado" apunta a "matar al dragón inflacionista", fundando un credo, luego extendido, de que es más importante mantener bajos niveles de inflación que lograr pleno empleo, lo que afecta cualquier pretensión redistributiva. Más ampliamente, se apunta a la necesidad de introducir formas de mercado en los espacios que la sociedad del bienestar había cubierto con servicios públicos. Se propaga el discurso de la ineficiencia de los servicios estatales y, luego, la legitimación de su privatización posterior.

No extraña el hecho de que, de la mano de la recuperación de estos idearios liberales sobre una concepción economicista de la vida social, se restituyan en los años ochenta los enfoques asociados a la teoría de la elección racional en la sociología y en la ciencia política, que recuperan un individualismo metodológico que relativiza el peso de las estructuras sociales. Su aplicación a los estudios sociales y políticos es una reposición del hombre económico y la primacía de un nuevo economicismo. Tal tendencia al uso del enfoque económico en la explicación de fenómenos no económicos se ampara en varios supuestos, anidados en lo que sus defensores entienden por comportamiento racional, como la idea de que el individuo tiene un plan coherente e intenta maximizar la satisfacción de sus preferencias, a la vez que busca minimizar los costes. De ahí que tal racionalidad implica la existencia de un orden de preferencias en el individuo ante las diversas opciones, entre las cuales se infiere una "función de utilidad". Más allá de lo polémico de estos y otros supuestos subyacentes en tales formulaciones, lo relevante para nuestra discusión es que ellas se extienden sobre el análisis de la vida social y los comportamientos políticos, hasta hacerse dominantes. Aunque los antecedentes de este uso del hombre económico como unidad epistemológica son cifrados, por algunos, en Hobbes y su idea de un mundo poblado de agentes racionales e interesados; o en Adam Smith, que empleó su razonamiento económico para explicar la acción 
política; o en las reformas utilitaristas de inicios del siglo XIX, que invocaban una lógica económica; lo cierto es que no es sino en nuestros tiempos que comienza a emplearse un enfoque económico para abarcar facetas muy disímiles de la vida social.

Más allá de sus adversarios keynesianos, las críticas al enfoque neoliberal abarcan una relevante línea de pensamiento sociológico y también liberal, que se desarrolla por todo el siglo XX hasta nuestros días, y afirma, más allá del sujeto del economicismo liberal, las bases sociales de la subjetividad. Ello introdujo la cuestión de cómo concebir las instituciones mediadoras en la formación de la personalidad social en una sociedad democrática. Un dilema al que no es ajeno, incluso, un liberalismo político que critica el carácter de esa formulación austriaca por economicista e individualista, y su posterior expresión monetarista; y que por eso alega un carácter político antes que económico del ser humano. Hay en Aron, por ejemplo, una defensa de enfoques no economicistas en las ciencias sociales, desde una aproximación genuinamente liberal a la política. ${ }^{4}$

En una formulación de similar orientación, Arendt reclama la primacía de la política como espacio de la vida humana. Su opuesta, la esfera privada — entendida ya sea bajo la forma clásica de la vida familiar dentro del hogar o, bien, bajo la forma moderna de instituciones privadas de la llamada "sociedad civil" o del "mercado"-, la entiende precisamente como aquel ámbito de la vida que se resta de la coexistencia con los demás, que se retira del encuentro con otros y que, por tanto, busca garantizar, bajo criterios valóricos, ideológicos o legales, cierto orden o reglas de convivencia que serían inaplicables a la irreductible contingencia de la esfera pública. Para Arendt (2009), el individuo reducido a la lógica de la necesidad en la que los hombres sobreviven no alcanza la posibilidad de la libertad en la que los hombres, en el espacio público, arriesgan sus vidas. De esto se desprende que la esfera privada es constitutivamente apolítica o, más bien, anti-política, mientras que es sólo en la esfera pública donde la política puede realmente acontecer. Lo que hay aquí es una concepción de la esfera pública para una comprensión distinta de la política. La esfera pública no es un espacio donde el consenso, la armonía y la paz estén garantizados, menos

\footnotetext{
${ }^{4} \mathrm{Al}$ respecto, ver Aron (1991).
} 
aún un espacio que por algún designio providencial esté destinado al acuerdo y a la formación de una identidad fija y resuelta. Pero es en esa esfera donde, para Arendt, se puede desplegar y afirmar la condición propiamente humana, esto es, el espacio donde cada ser humano puede expresar su discurso y realizar una acción efectivamente dotada de sentido y valor; en tanto discurso y acción son inconcebibles en completo aislamiento, y nunca logran alcanzar la profundidad y la potencia de la que son capaces cuando no se es escuchado y visto por otros. De ahí que en la esfera privada no puede haber discurso y acción propiamente políticos; allí las condiciones de su despliegue están limitadas a un intercambio privado. Sólo confrontados a la diferencia y a la pluralidad es posible que discurso y acción tengan un sentido y un efecto políticos.

Arendt aboga así por una politización de la sociedad no como restricción de libertad, sino todo lo contrario. De ahí también su desconfianza en el Estado como poder burocrático, que simplemente reemplaza la primacía de las estructuras de poder del ámbito privado por otras nuevas, igualmente perversas. No plantea el dilema como oposición entre mercado y Estado, puesto que el Estado también, en caso de ser capturado - en cierta similitud a la crítica de Hayek al corporativismo-, disuelve la esfera pública deliberativa. Así, no es la socialdemocracia una solución satisfactoria. Pero es claro que subyace aquí una perspectiva ontológica del ser muy distinta a aquélla de los anotados economistas austríacos.

Es una idea distinta de libertad. No se reduce al individuo, ni limita su razón a la dinámica de fijación de precios, sino que se extiende a la sociedad, que, organizada en polis, es reflexiva sobre su destino. Es una idea de libertad ligada a la tradición kantiana, entendida como autodeterminación y no la simple ausencia de coerciones, como ocurre en la formulación negativa de Hayek. En la polis, y sólo en ella, cada individuo alcanza su libertad, por cuanto es capaz de orientarse más allá de sus necesidades. La sociedad no aparece, entonces, como simple sumatoria de los individuos particulares, sino como deliberación pública y racional.

Si el ser humano es político antes que privado, la desigualdad aparece entonces como problema político. Del otro lado del Atlántico, en un debate más tardío pero trascendente, C. Wright Mills (1986) reprocha a la discusión planteada por este liberalismo económico el hecho de 
que no considere el papel de los grupos que ocupan posiciones de poder en el ámbito económico y político. ${ }^{5}$ Se abría así la interpelación por el carácter social de las élites. Se inquiere por el interés tras el programa hayekiano, como voluntad — colectiva, según hemos visto - de despolitización. Por esto mismo, Raymond Aron reclama desde el propio liberalismo político que las reformas propugnadas por los seguidores de la escuela austriaca sólo podrían llevarse a cabo bajo una restricción inaudita de la esfera pública — esa que defiende Arendt como esencial a la libertad—, y, por ende, sólo podría defender su concepción de libertad cancelando la de quienes la entienden de otro modo (Aron 1991).

\section{DESIGUALDAD, ESTADO Y MERCADO. LAS CONDICIONES DE LA DISCUSIÓN ACTUAL ${ }^{6}$}

Tal como se ha señalado, la pregunta sobre la naturaleza política de la desigualdad remite al estatuto del mercado en la sociedad. En otros términos, hace referencia al sometimiento de la economía a la política, y arrastra la preocupación por el hecho de que ello resulte posible preservando la libertad, sin que exista una asociación entre regulación o planificación y autoritarismo. Plantea, en fin, el dilema de cómo compatibilizar el libre mercado con el interés general. Empero, aparte de sus espinosos antecedentes intelectuales y políticos, las condiciones de la discusión actual en nuestra experiencia aportan su propia dosis de complejidad a esta cuestión.

Uno de los idearios más recurrentes en el proceso de transición a la democracia en Chile ha sido aquél que se establece en torno al debate entre Estado y mercado. Ante un curso de privatización heredado de la etapa autoritaria, se argüía la necesidad de anteponer el Estado, como sinónimo, si no directamente de igualdad, al menos de reducción de las extremas desigualdades heredadas, que resultaban de difícil legitimación en la etapa democrática. Con ello se fundaron relevantes idearios y discursos de legitimación, sobre los que se buscaba cifrar el sentido de la distinción no sólo entre la perspectiva socialdemócrata y la neoliberal,

${ }^{5}$ Véase Wright Mills (1940) o bien, sobre los enfoques del objeto en cuestión, Gerth y Wright Mills (1971).

${ }^{6}$ Para un mayor desarrollo de estos temas ver Ruiz (2017). 
sino, más allá, también entre demócratas y defensores del autoritarismo, y hasta entre izquierda y derecha mismas. Sin embargo, la experiencia indica que, a más de dos décadas y media de esta recuperación estatal concebida, la desigualdad no remonta significativamente, y aunque en los últimos años ha disminuido en términos de distribución del ingreso sigue siendo una de las más altas de América Latina y de los países OCDE. ${ }^{7}$ En efecto, después de los tres primeros lustros de crecimiento sostenido del gasto social estatal desde el fin de la noche dictatorial - especialmente en las áreas de salud, educación o vivienda, en que se multiplican en varias veces los volúmenes heredados- resulta que la desigualdad, especialmente en términos de la concentración de la riqueza y el poder, empeora o se mantiene mal. Las disparidades habidas ubican a la experiencia chilena entre las peores de la región, incluso a escala mundial. Ello en plena experiencia democrática. Este dilema no puede dejar de llamar la atención, y sus efectos se propagan hasta el ámbito de la política. La asociación simple entre Estado e igualdad no sólo tambalea con esta experiencia, sino que extiende sus extravíos sobre las pretensiones de construcción de cultura política que se buscaban cifrar en ella.

El problema no se reduce, por lo demás, a una situación de incapacidad estatal por detener la expansión de las brechas sociales a raíz de un aumento de la pobreza. La paradoja aparente estriba en el hecho de que la pobreza disminuye precisamente en este período. O sea, con oscilaciones, las desigualdades se mantienen relativamente altas (PNUD 2017), al mismo tiempo que la pobreza disminuye. El problema está en otra parte. La concentración de la propiedad y del ingreso se desata en pleno período democrático, constituyéndose en las bases más relevantes del crecimiento de la desigualdad en medio de un contexto de

${ }^{7}$ El Índice de Gini toma valores de 0 a 100 (o de 0 a 1, según como se exprese), siendo 0 el máximo nivel de igualdad y 100 el máximo nivel de desigualdad de distribución de los ingresos de la población. Pese a que este indicador tiene dificultades para registrar las grandes fortunas, en 1990-2000 el Índice de Gini se eleva de 52,1 a 54,9, y posteriormente decrece hasta alcanzar un valor de 47,6 en 2015 (PNUD 2017). Chile es el segundo país más desigual de la OCDE después de México (de 37 países, 35 registran un Índice de Gini bajo los 40 puntos, en tanto 18 lo hacen bajo los 30 puntos). Ver http://www.oecd.org/social/income-distributiondatabase.htm. En América del Sur, año 2013, Chile sólo es superado por Colombia y Brasil (Banco Mundial). Ver https://datos.bancomundial.org. 
crecimiento económico y de elevación general —aunque muy desigual, valga insistir- de los ingresos.

Peor aún, en el centro de la extendida desidentificación actual con la política, y de agudo divorcio entre Estado y sociedad, está el hecho de que en una medida importante muchos de esos cursos de concentrada acumulación de la riqueza ocurren al amparo del propio Estado. Las subvenciones estatales que crecen en este lapso se destinan en gran parte a subvencionar las ganancias de un enjambre de empresas, que crecen en los nichos de acumulación regulados que han dejado unos servicios públicos que, para ello, se mantienen convenientemente desmantelados y en estado crítico. Esta suerte de capitalismo de servicio público, entonces, crece en paralelo y en forma orgánicamente dependiente con tal expansión del gasto estatal, precisamente, en las áreas de atención social.

No es difícil advertir la cantidad de incongruencias que esta experiencia histórico-concreta plantea respecto a los idearios invocados, especialmente en términos del pensamiento socialdemócrata y del propio liberalismo económico. Más allá de los ideologismos que impiden verlo, resulta que gran parte de ese acrecentado Estado ha terminado subvencionando - en democracia - acumulaciones privadas como prestadoras de servicios sociales en la educación, la salud, la vivienda "social" y otras esferas.

La paradoja -ideológica - crece al constatar que los niveles de concentración de la propiedad y de la riqueza que un proceso de estas características estimula no sólo se convierten en una de las explicaciones principales de la desigualdad actual, dada la concentración que produce, sino que además terminan arrojando unas modalidades de dicha concentración que actúan en contra de la propia competitividad - traicionando a Smith-, la innovación y otras características relativas a la "destrucción creativa" que Schumpeter atribuye a la competencia capitalista. ${ }^{8}$

De este modo, en contra de extendidas vulgatas tanto de izquierda como de derecha, el neoliberalismo chileno no resulta necesariamente en menos Estado, y tampoco ocurre aquello de que a más Estado habría

${ }^{8}$ En el caso de la educación superior es claro cómo, a partir de estos subsidios estatales, lo que se estimula no es la calidad, sino la proliferación de una lucrativa oferta cara y mala (las excepciones son muy acotadas). 
menos mercado, entendido como esfera económica privada. Lo cierto es que hay otro Estado, y que a su amparo han surgido nuevas formas de diferenciación social y se ha profundizado la concentración de la riqueza y del poder. ${ }^{9}$

Si para unos el Estado aparecía como un centro de contención del mercado, la experiencia desvanece tal ilusión. Para otros, si el Estado era sinónimo de restricción de libertades, del desarrollo del individuo y de las oportunidades, resulta que respecto de tales libertades y oportunidades, situadas en un ideal de mercado - entendido como esfera competitiva y multiplicadora de ellas-, ocurre otra paradoja ideológica, pues se trata de intereses privados que crecen al amparo del intervencionismo estatal, de la constitución de nichos de acumulación regulados por esta peculiar forma de planificación. ${ }^{10}$ Es decir, a través de la cooptación de la iniciativa estatal en nombre de la libertad, se termina capturando el mercado, anulando la competencia y, por tanto, restringiendo toda posibilidad de que represente un espacio de realización de la invocada libertad creativa del individuo.

La concentración así estimulada no redunda en más oportunidades ni en alguna igualdad referida a ellas. No sólo ocurre un fomento esta-

${ }^{9}$ Pese a que la desigualdad de ingresos disminuye ligeramente, el problema central en Chile es la concentración de la riqueza, el poder y el prestigio social. Según un estudio de The Boston Consulting Group, el patrimonio total de los hogares chilenos se expandió 7,69 por ciento en 2016 frente al año anterior, alcanzando una cifra de US\$ 393.080 millones. De esa cifra, el 7 por ciento se encuentra invertido en el extranjero. Un informe del PNUD (2017) señala que alrededor del 75 por ciento de los ministros, el 60 por ciento de los senadores y más del 40 por ciento de los diputados del período 1990-2016 asistió a colegios de élite, estudió carreras universitarias de élite, o ambas cosas.

${ }^{10}$ Un informe del PNUD $(2017,38)$ concluye: "Los gobiernos democráticos desde 1990 privilegiaron la expansión del gasto público en educación, salud y vivienda. Pero el acceso a estos servicios es segmentado por clases sociales, desde servicios gratuitos provistos por el Estado para los más pobres a servicios de calidad que las clases altas compran en el mercado. (...) La población más pobre accede a servicios que le entrega gratuitamente el Estado en instituciones públicas y que tienen problemas de calidad (educación) o de largas esperas (salud), los sectores medios acceden preferentemente a servicios privados de mejor calidad, que son cofinanciados por ellos y el Estado (educación particular subvencionada, atención de libre elección en Fonasa), y los grupos de altos ingresos adquieren servicios privados de mayor calidad y costo, sin mediar financiamiento público. En los países de la OCDE la distribución está mucho menos segmentada; las transferencias públicas se distribuyen de modo más parejo entre la población”. 
tal de la desigualdad en la distribución del ingreso, sino que también la acumulación de carácter privado que ello promueve opera en forma contraria a la igualdad de oportunidades. Es una expansión mercantil orgánicamente vinculada a una planificación estatal. De modo que tampoco hay una multiplicación ni una equitativa distribución de las oportunidades de emprendimiento, sino su concentración en pocas manos, en detrimento de la libertad de competencia. Tal expansión de las esferas privadas no reporta más mercado, en el sentido clásico de su acepción.

En definitiva, no parece haber más libertad. Pero no sólo de emprendimiento empresarial. Tampoco a nivel del individuo que, sin capacidad de tal emprendimiento, sufre sus estragos en la base de la sociedad. Pues la misma expansión de los mercados sobre los derechos sociales no sólo impacta en una extrema mercantilización de las condiciones de reproducción de la vida social, al privatizar extendidamente cuestiones como la salud, la educación o las pensiones, sino que, asimismo, introduce unos enormes y conocidos niveles de incertidumbre en los individuos, propios de una pérdida de soberanía sobre sus propias vidas. En definitiva, también hay una pérdida general de libertad a nivel de la vida cotidiana, de la reproducción individual.

En suma, ocurre que, si bien más Estado no significa una expansión de lo público, tampoco una expansión privada significa una ampliación del mercado, de la competencia, las oportunidades y las libertades supuestamente asociadas a ello. Es decir, más esfera privada no significa más mercado ni oportunidades y libertades para todos. Al fin y al cabo, en nuestra experiencia reciente, ambas construcciones ideológicas - de las que dicen asimilarse a los respectivos ethos socialdemócratas y liberales criollos - resultan incongruentes, en grado sumo, con el sentido original de los preceptos en que dicen ampararse.

\section{INCONGRUENCIAS IDEOLÓGICAS Y CRISIS DE LA CULTURA POLÍTICA}

Según se observa, estamos ante profundas incongruencias en el uso del ideario liberal y socialdemócrata, entre un Estado que no trae igualdad y un mercado que no trae libertad, y que cuentan entre sus efectos el ahondamiento de la crisis actual de la cultura política, como expresión de una extendida desidentificación de la sociedad con la política y 
con el Estado. A fin de cuentas, la pretendida racionalidad - tan debatida, como vimos - no aparece por ningún lado, y, con ello, tampoco la posibilidad de que estos idearios invocados actúen con alguna incidencia en los procesos concretos de construcción de sentido que operan a nivel de los individuos.

En semejante andar, aparece el hecho de que la simple defensa del Estado no es alternativa, a pesar de una izquierda que apela ciegamente a ello. Ha sido más mercado, y en una forma que, además, no ha sido más libertad, como tampoco más individuo. Acaso, peor aún, no ha sido tampoco más justicia, más democracia ni más ciudadanía.

La crisis de legitimidad actual de la política tiene que ver con ello. Más aún, la crisis general de las élites, incluida la económica. La incongruencia entre la permanente apelación a los idearios de libertad e igualdad y los resultados concretos de la sociedad construida en más de 25 años de régimen democrático redunda — como se señalaba - en un divorcio entre política y sociedad, y en una deslegitimación generalizada de la primera, que tiende a ser vetada como esfera de diálogo y resolución de diferencias ideológicas, pero sobre todo como esfera de construcción de sentido para los proyectos de vida de los integrantes de la segunda. No sólo aparecen cuestionados principios como la igualdad - incluso la de oportunidades_-, sino que también la justicia y la propia participación democrática. De tal suerte que, en función de su reproducción social, los individuos tienden a proyectar su vida en ausencia de marcos de sentido vinculados a estas pretendidas instituciones sociales y normativas ligadas a la esfera de la política.

Es imposible atender seriamente la crisis de legitimidad de la política chilena sin encarar los perniciosos efectos de la utilización espuria de estas banderas en la actualidad. Es necesario asumir que no es posible trasladar mecánicamente la dicotomía entre igualdad y libertad a la experiencia chilena, pues, en base a la experiencia histórica reciente, tan ajeno aparece el pensamiento socialdemócrata a la Concertación, como el liberalismo a la derecha, pese a que los invocan, respectivamente, como bases de sus idearios y programas políticos.

Por ello, estas tradiciones teóricas están vacantes. Hay una utopía izquierdista del Estado, como una de la derecha sobre el mercado que no son más que mecanicismos abstractos. El problema es que esto resulta indicativo de un vacío en la cultura política y, con ello, de ur- 
gencias para su refundación, para la reconstrucción de su anclaje en la sociedad y de su legitimidad. Del mismo modo, estas incongruencias anotadas remiten a la incapacidad de las fuerzas políticas que gestan la transición a la democracia para realizar un debate sustantivo sobre los límites de la modernización que instala la dictadura, y, más aún, para emprender las reformas necesarias para abrir nuevos ciclos de desarrollo y bienestar para el país.

Es el agotamiento de los términos al uso de la contraposición entre Estado y mercado como base de la cultura política de la transición a la democracia. De ahí la despolitización y el vacío ideológico, la vacancia política de la "modernidad" chilena. La propia crítica de Weber a la falsa modernidad y su atención sobre la permanencia de formas estamentales contrapuestas al genuino liberalismo político no pueden resultar más atingentes. Otro tanto cabe anotar de la reubicación de las nociones de lo público más allá de lo estatal y de lo privado más allá del mercado, que aborda especialmente la obra de Arendt.

La discusión debe ubicarse en la connotación política que adquiere hoy. Los principales actores de la política chilena de las últimas décadas omiten las críticas y advertencias que los mismos idearios y pensadores invocados alzan como banderas. Por ejemplo, no se mira (i) la defensa de Rawls acerca del valor funcional de la desigualdad, valor amparado en una competencia y una equidad de derechos y oportunidades, no en diferenciación estamental; (ii) la propia crítica de Smith a la concentración como limitación al mercado o la crítica de Hayek - no muy popular en Chile - al corporativismo - léase "estamentos"- en función de la libertad; y (iii) la recuperación del sentido originario de la idea de Schumpeter que supone, en la competencia efectiva, una "destrucción creativa" como motor económico, contraria a la acumulación basada en nichos regulados, y a la consiguiente contraposición entre rentismo y emprendimiento.

Pero el problema es la política y eso requiere otras recuperaciones. Como la preocupación de Arendt, en su crítica al totalitarismo, por una política concebida como libre contraposición y concurso de proyectos. Volver a Aron y su propuesta de la democracia como consenso o pacto social no determinado (en nuestro caso, agréguese, por entelequia tecnocrática alguna). Es una discusión que emana de las preocupaciones por la fractura social a que llegan las experiencias económicas liberales extremas. De ahí el llamado de Polanyi contra la mercantilización excesiva y sus limitaciones a la integración social. 


\section{REPENSAR LA POLÍTICA COMO LIBERTAD Y COMO DERECHO A LA SOCIEDAD}

Los estrechos límites a la imaginación política que nos ofrecen los marcos de la transición se reflejan en esta famélica concepción de dos componentes fundamentales del ideario de la modernidad: libertad e igualdad. La libertad se nos presenta reducida a la libertad del individuo, desconociendo toda epistemología que reconozca su condición societal; es decir, perdiendo de vista los determinantes sociales que inciden en la capacidad de ejercer la libertad, en especial aquellas dimensiones de la libertad que sólo pueden realizarse colectivamente.

De esta forma, libertad se reduce a un principio negativo, una especie de "derecho al aislamiento" que invocaba la crítica de Marx. Ya Isaiah Berlin advertía a mediados del siglo pasado sobre los riesgos que la expansión de la libertad positiva representaba para la libertad negativa (Berlin 2004). Los derroteros del neoliberalismo alertan no sólo sobre el ensombrecimiento de la idea de libertad; también lo hacen respecto de sus efectos sobre la idea misma de racionalidad en las bases del pensamiento moderno. Tras reducir la libertad a la mera experiencia individual, se la asocia con el comportamiento del individuo relativo a sus preferencias ante el mercado, es decir, relacionado con los precios. Se limita así la razón a los precios, con lo que se arrasa la racionalidad como principio secular.

Así, se gesta una derecha intransigente, cuyo ideal de libertad es opuesto a la idea misma de la política, pues se opone a la deliberación como racionalidad socialmente construida. En otras palabras, se trata de una libertad que se opone, por tanto, a la democracia como tal. No tiene nada de sorprendente que la libertad de esta derecha pueda lograrse bajo regímenes autoritarios; un paradigma ante el cual lo social sólo aparece como un modo compensatorio, de ahí el "Estado subsidiario" en la concepción al uso. Un ideal de cosas que niega cualquier tipo de deliberación social sobre el problema de la construcción de la sociedad, en especial los distintos tipos de libertades que los individuos puedan levantar como más importantes que otras; como, por ejemplo, la libertad para participar de una sociedad con políticas que enfrenten la desigualdad o, incluso, de perseguir una experiencia abiertamente igualitaria. Pues, como se sabe, las prioridades cambian con la condición social. 
Semejante es el curso que sufre la igualdad cuando se la reduce al igual derecho a participar de la libertad negativa. Es sabido que las bases estructurales e institucionales de una comunidad socioeconómica refieren al hecho de que no coexistan varios países al interior de uno. Ese es el tema de la igualdad, es decir, el establecimiento de distancias mínimas y razonables, que no pueden ser fijadas para siempre, sino que emanan del consenso social, entre los miembros de una sociedad. Ello va mucho más allá de las visiones que reducen el tema de la igualdad en las sociedades a la igualdad de oportunidades (Dubet 2010). Si la equidad supone una base individual, la igualdad exige redistribución de poder y riqueza, es decir, exige intervención de un ente distribuidor, que es el Estado.

Pero un Estado, para tal tarea, requiere un carácter democrático. En otras palabras, un Estado, para alcanzar tal objetivo, requiere evitar un restrictivo carácter burocrático, susceptible de una captura por intereses corporativos. Tal búsqueda de la primacía del interés general requiere primar sobre los procesos de construcción del Estado. Y ello sólo es posible a través de la expansión de la política, en un proceso apuntado a convertir a la acción estatal en un espacio de articulación de las diferencias legítimas presentes en la sociedad. Pues, al contrario, si la ausencia de equidad destruye las vidas individuales, la ausencia de igualdad destruye la vida de las sociedades, transforma una sociedad en varios mundos yuxtapuestos que no se reconocen como parte de un espacio o un proyecto común.

En definitiva, hay que replantearse críticamente la forma en que los basamentos ideológicos de la modernidad fueron asumidos políticamente en la experiencia chilena. Si más Estado no ha significado menos mercado, ni este último más oportunidades, libertades ni desarrollo del individuo, es porque la única garantía de ello está en la democracia y en más ciudadanía, bienes que no se han expandido precisamente. Por el contrario, las constricciones a la democracia y a la ciudadanía, a la política en definitiva, han operado facilitando estos desarrollos del Estado y el mercado en formas incongruentes con los propios idearios que invocan sus discursos de legitimación.

Una esfera política genuinamente democrática debe abrir la búsqueda de equilibrios socialmente aceptables entre el rol de los individuos y aquél de los grupos sociales y las organizaciones políticas, 
como representación de dichos intereses, en la construcción genuina de consensos. Y eso implica, de forma inevitable, reconstruir la polis; una tarea pendiente de la transición chilena a la democracia, evitando para ello, entre otras cosas, volver a la manida reducción de lo público a lo estatal, ensanchando los horizontes de lo primero necesariamente más allá del Estado.

La utopía conservadora y elitista de la posibilidad de una política - y una economía - sin sociedad que primó en la transición, en el momento de concebir la política democrática, y que hasta hoy prima sobre una esfera política ensimismada, terminó apelando al individualismo como única forma del individuo. Sin embargo, si esto pareció posible en unos inicios marcados por la desarticulación social heredada del período autoritario, producto de las transformaciones económicas e institucionales efectuadas bajo la dictadura, que alteraron las bases de sustentación de la mayor parte de los actores sociales subalternos más protagónicos del siglo XX chileno, luego, desde el "quietismo" social de los años noventa, brotó un heterogéneo y variopinto malestar social, una sociedad fruto de las propias transformaciones neoliberales, que no encuentra cabida en las referencias políticas de la transición (Ruiz 2015).

La democracia entendida como proceso amplio de deliberación y de soberana construcción de una racionalidad común legítimamente sancionada permite distinguir entre un Estado democrático y uno simplemente burocrático, el que, como el vigente, a pesar de erigirse en nombre de la democracia se basa en una constricción de tales deliberación y racionalidad. La extrema concentración del ingreso, la riqueza y las oportunidades que ocurre en la experiencia democrática reciente en Chile es expresión de procesos de colonización del Estado por parte de intereses particulares en extremo excluyentes, cuya naturaleza rentista se ampara precisamente en la posibilidad de la captura de la acción estatal; un curso que requiere de pesadas constricciones sobre los alcances de la ciudadanía y el espacio público.

$\mathrm{Si}$, por una parte, la tesis del Estado como centro de todo, relativa a los socialdemócratas, se abstrae del carácter social restrictivo del Estado, producto de las alianzas sociales que dominan sus procesos de construcción en cada momento histórico; por la otra, la libertad individual del mercado alegada por el liberalismo - y su correlato de racionalidad fundada en la conducta individual de elección - apela a una libertad y 
una racionalidad no deliberadas socialmente. Ello supone dificultades prácticas para ambos idearios, que resultan profusamente evadidas en nuestra experiencia política por sus representantes criollos. Las diferentes restricciones que uno y otro efectúan a la expansión irrestricta de la política siempre han requerido, en todas las experiencias, de complejas exigencias a la imaginación para alcanzar consensos capaces de alguna legitimidad social suficiente; unas dificultades que en la experiencia chilena se optó por ignorar, al amparo de una simple desarticulación social heredada por todo fundamento de la llamada "gobernabilidad democrática"; un panorama en que la intelectualidad cortesana se acomodó al agotamiento de la imaginación política.

Por el contrario, la crisis actual requiere de una expansión de la esfera de la política, capaz de conducir a la expansión social de la libertad, la deliberación y la razón. Es decir, de una recuperación de las promesas incumplidas de la modernidad, su radicalización. Una deliberación que permita incluir las diversas aspiraciones de igualdad y su resolución democrática, las demandas de inclusión y la introducción de los propios principios éticos de la democracia en el funcionamiento de los mercados. Se trata de un sometimiento de la economía a la política genuinamente democrática. La resolución del problema de la desigualdad queda así en manos de una política genuinamente democrática, de una ciudadanía libre de ejercer una amplia concurrencia de idearios, en formas no predeterminadas, sino entregadas a los consensos resultantes. De este modo, la solución del problema de la desigualdad se imbrica con la resolución del problema del derecho de los individuos a la sociedad, con el derecho común de humanidad. Y ello remite a la autodeterminación de la sociedad como paradigma de la razón y la libertad, a la que sólo se puede aspirar a través de la política democrática. En tal sentido, política es libertad.

\section{REFERENCIAS}

Álvarez-Uría Rico, Fernando. 2005. “Sociología y libertad: el debate entre Friedrich Hayek y Karl Mannheim sobre el estatuto del mercado en la sociedad". Arxius de Sociologia 12-13: 13-40.

Anderson, Perry. 2008. Spectrum. De la izquierda a la derecha en el mundo de las ideas. Madrid: Akal.

Arendt, Hannah. 2009. La condición humana. Madrid: Paidós. 
Aron, Raymond. 1991. Ensayo sobre las libertades. Madrid: Alianza.

Berlin, Isaiah. 2004. Sobre la libertad. Madrid: Alianza.

Dahrendorf, Ralf. 1962. Las clases sociales y su conflicto en la sociedad industrial. Madrid: Rialp.

Davis, Kingsley \& Wilbert Moore. 1972. "Algunos principios de la teoría de la estratificación”. En Clases, status y poder, editado por R. Bendix \& S. Lipset. Madrid: Euramérica.

Dubet, François. 2010. Repensar la justicia social. Contra el mito de la igualdad de oportunidades. México: Siglo XXI.

Elias, Norbert. 1987. El proceso de civilización. Investigaciones sociogenéticas y psicogenéticas. México: FCE.

Gerth, Hans Heinrich \& Charles Wright Mills. 1971. Carácter y estructura social. La psicología de las instituciones sociales. Buenos Aires: Paidós.

Hayek, Friedrich. 1937. "Economics and Knowledge". Economica 4 (13): 33-54.

-1941. "Planning, Science and Freedom". Nature 148: 580-584.

-2008. Camino de servidumbre. Madrid: Unión Editorial.

Marx, Karl. 1967. "La cuestión judía". En La sagrada familia y otros escritos filosóficos de la primera época, 16-44. México: Grijalbo.

PNUD. 2017. Desiguales. Orígenes, cambios y desafios de la brecha social en Chile. Santiago: Uqbar Editores y PNUD.

Polanyi, Karl. 1992. La gran transformación. Los orígenes politicos y económicos de nuestro tiempo. México: FCE.

—. 2008. Essais, editado por Michele Cangiani \& Jérôme Maucourant. París: Seuil.

Rawls, John. 1979. Teoría de la justicia. México: FCE. -1993. El liberalismo político. México: FCE.

Remmling, Gunter W. 1982. La sociología de Karl Mannheim. México: FCE.

Ruiz Encina, Carlos. 2015. De nuevo la sociedad. Santiago: LOM - Fundación Nodo XXI.

—. 2017. "Socialismo y libertad. Notas para repensar la izquierda". En Chile actual: crisis y debate desde las izquierdas, editado por Faride Zerán. Santiago: LOM.

Wapshott, Nicholas. 2013. Keynes vesus Hayek. El choque que definió la economía moderna. Barcelona: Deusto.

Weber, Max. 1964. Economía y sociedad. Esbozo de sociología comprensiva. Madrid: FCE.

Wright Mills, Charles. 1940. "Man and Society in an Age of Reconstruction. By Karl Mannheim, Edward Shils". American Sociological Review 5 (6): 965969.

1986. La imaginación sociológica. Santiago: FCE. EP 